\title{
Formation of Creative Thinking of Future Teachers on Physics by Means of Information Technologies
}

\author{
Sherzod Ramankulov, Kamalbek Berkimbaev, \\ Sattarbek Bekbayev, Umirzak Abdumanapov, \\ Ganiya Ormanova \& Aliya Sarybaeva \\ Department of Natural Sciences, \\ Kh.A.Yasawi International Kazakh-Turkish University, \\ Turkestan (161 200), Kazakhstan \\ sherzod.ramankulov@iktu.kz
}

\begin{abstract}
This article deals with scientific and methodical fundamentals of use of computer models of experiments and demonstrations, and also virtual laboratory complexes in forming of creative thinking of the future teachers of physics. What is happening in the last decade the total process of Informatization of education occupies a special place include information technology in the teaching of physics. This is due to at least two circumstances. First, the role of physics as the fundamental basics of computer operation, achievements of modern information and communication technologies. Secondly, the fact that physics is the most developed area of application of these technologies. ICT are as innovative technologies, transformative learning in relation to such of its essential properties as the target orientation, the nature of the interaction of teacher and students, their position in the course of training. Currently, International Kazakh-Turkish University named after $H$. A. Yasawi paid great attention to the development of technical basis the use of information and communication technologies in teaching students of physics, to develop electronic resources for use in teaching physics. Using computer models, experiments and demonstrations, you can compensate for the lack of equipment in the physical laboratory, and thus, to teach students to independently produce physical knowledge in the course of physical experiments on virtual models, that is, there a real opportunity to develop students creative thinking and enhance cognitive activity in physics.
\end{abstract}

Keywords-future teachers of physics; information technology; computer models; electronic resources; creativity; creative thinking.

\section{INTRODUCTION}

The new situation in society and the education system requires the preparation of teachers of a new type, capable of working in challenging conditions. The teacher of today must not only possess a high level of General culture, psycho-pedagogical competence, but also nontraditional approach to solving various situations, to organize their activities in a creative manner.

To ensure the quality of professional preparation, the transition from traditional activities to research. In this regard, the role of self-education, self-identity, and of particular importance is the development of creativity as one of the factors of successful implementation of professional activity of any specialist. The development of creativity of future teachers is impossible without understanding the studied discipline, because understanding is an adequate translation of knowledge, which is the resultant of knowledge and experience [1].

Creativity (borrowing from English literature, from lat. creatio - creation) is a term introduced by $\mathrm{P}$. Torrens, refers to the ability to be creative in the broadest sense; the ability to produce new ideas and find innovative solutions to problems Researchers Leonard and Swap , "Nurturing creativity" (2010) say that "creativity" is the process of development and expression of new ideas, which can also be useful. They note that "creativity is not a talent, it can be defined as a purposeful process for organizations which require an approach that maximize individual talents, experience and qualifications" (D. Leonard and W. Swap, 2010) [2-3].

Physics as an academic discipline has a huge potential in the development of creativity. This is determined by a variety of physical disciplines (mechanics, molecular physics, thermodynamics, quantum physics, optics, physics of continuous media, electrodynamics, and so on), in studies which used different methods and techniques of activity, providing wide opportunities for both teacher and student, as well as the implementation of various forms of educational practice, enabling the development of creativity.

The results of our study show when studying and perceptions of students of the fundamentals of optics associated difficulties, due to the abstractness of optical concepts, conflicting properties of light and low visibility of quantum objects of study; a) the imperfection of the contents of this section in existing programs in physics b) the use of teachers on the lessons of physics verbal learning method as the principal; c) lack of experimental support for the learning process optics associated with disabilities the full-scale experiment (not all optical the phenomenon can be shown in terms of the physical laboratory, experiments are not always sufficiently clear and is mostly qualitative in nature; the devices are complicated and inconvenient in service), and lack of the necessary material conditions for it[4].

In the modern socio-economic conditions of society one of the important tasks of education is the development of personal qualities of future teachers, the development of his thinking, creativity, values and attitudes. We 
believe that promising for the solution of these problems is the use of new information technologies in teaching physics, in particular, when learning of optics. Their use at the present stage of training due to several factors. First, due to the social and economic achievements have computers. The quantity and quality of ready-made software products on the physics is such that allows to implement various learning technologies. Secondly, the simulation using computer technology allows you to get a visual dynamic illustrations not only of the observed physical processes and phenomena, but is not available for observation in a real experiment, and also allows you to provide greater flexibility to conduct computational physics experiments and solving various experimental tasks. And the computer using it is associated with modern accessories allows for a high level investigation of the various study processes. Accordingly, the use of new computer experiments (demonstration and laboratory) training optics allows to overcome the mentioned related experiment problems.

\section{PURPOSE OF RESEARCH}

Use of information technology, computer models, electronic resources in a higher educational institution for formation of creative thinking of students.

\section{RESEARCH METHODS}

The general scientific: analytical (the analysis of scientific literature on psychology, pedagogics, physics on a studied subject; the analysis of manuals on training in physics); the pedagogical: supervision and material generalization on professional training of future specialists - physicists; questioning and testing; skilled and experimental methods: carrying out skilled training, pedagogical experiment, processing of mathematical and statistical data.

The created electronic textbook allows you easily find the information they need, return to the material, gives an opportunity to more fully explore the material, which makes a training manual attractive, affordable, and this in turn has a positive effect on the learner. The content of the material set out with the use of animation easy and accessible, clear. Text material is equipped with: illustrations, tables, graphic examples, facilitate the perception of the material, tests for the control of knowledge of students at the section. The results of the research can be used in training the future teachers of physics in the quality of material when teaching of the following disciplines: «Optics» of course «Physics», «Methods of teaching physics».

\section{RESULTS OF STUDY}

In our research "Formation of creative thinking of future teachers on physics by means of information technologies" we understand its correspondence of personal, cognitive and methodical concept to market society, innovative, physics and technology knowledge and qualification, information and technological skills, and the ways of development of scientific-theoretical bases.

The problem of improvement of professional training of future teachers - physicists, updated content and technologies of teaching is a constant object of active research and theoretical analysis. The improvement of professional training of future specialists - physicists in using the information technologies of great importance on the one hand, and on the other it is an effective technology and their application in the learning process.

To analyze the scientific-practical bases of improvement of professional training of future teachers of physics at the University, to identify the extent of its theoretical and practical elaboration on the basis of experimental verification and analysis of the comparison of the experimental and control groups of students of «Physics» Department, Natural Sciences Faculty of H.A.Yasawi International Kazakh-Turkish university, according to 5B011000 - Physics and 5B060400-Physics; to prove requirement and necessity to improve the professional training of the future specialists - physicists, to develop the information technologies to improve the training of future teachers of physics.

To prove the usage of information technologies scientific practically in improvement of professional training of future teachers of physics, proved in the principles of scientific character, problematical character of training, presentation, consciousness, independence and activization of activity, systematicness and sequence. Improvement of professional training of future teachers of physics on the basis of information technologies is realized by supply of educational process with training materials. At creation of electronic textbooks we were guided by the following principles:

i) Principle of scientific character. Providing the maintenance of a training material with scientific reliable information - expresses need of taking into account the last scientific achievements. Process of assimilation of a training material through the electronic textbook has to be created according to modern ways of scientific knowledge (experiment, comparison, control, abstraction, generalization, specification, analog, an induction and deduction, the analysis and synthesis, modeling methods), and also to the mathematical and system analysis.

ii) Principle of problem training. Training educational cognitive actions in case of importance. By search of solutions for problem situations students' thinking ability develops actively. It is more favorable to fulfill such didactic requirements with the help of electronic textbooks.

iii) The principle of presentation expresses need of formation of representations and concepts on the basis of all sensual perceptions of studied objects and their models. In the electronic textbook execution of the requirement of presentation has to be provided at new and high level. Use of elements of multimedia covers all channels of information perception of the person.

iv) Principle of interactivity, activization, organization of independent work. As the electronic textbook (ET) is 
intended first of all for independent work, the trainee has to approach to it consciously.

v) Principle of systematicness and sequence. Electronic forms have to allow easily and conveniently systematize all material of the textbook and arrange it in sequence of convenience for studying.

In additives to the pedagogical principles called above should master the following special didactic conditions connected with use modern information and telecommunication technologies (on a basis of Internet materials):

i) Adaptation condition. To adapt the electronic textbook under personal opportunities of a student. This is adapting knowledge in the course of training on psychological features of the student.

ii) Interactivity condition in training. In the course of training there has to be a connection between the student and the electronic textbook. ET has to provide interactive dialogue or feedback. The main condition of the organization of interactive dialogue feedback existence with the student using the electronic textbook.

iii) Computer visual condition. Comparative analysis of modern means of display of information (computers, multimedia projectors, virtual means, software), qualities of the electronic book.

iv) Condition of development of intellectual potential. To form different types of thinking by means of ET (algorithmic, visual image, reflexive, theoretical), ability to make the correct decision in difficult situations and qualification of information processing.

v) Condition of structurally functional connection. To specify all necessary training materials of ET[5].

vi) Condition of providing continuity of a didactic cycle of training.

Increasing of knowledge level of students according to the section of a course of physics of "Optics", and as ensuring quality of studying of separate subjects of discipline that in great degree can be promoted by use of information and communication technologies became the main task at creation of the electronic textbook.

The electronic textbook developed by us includes the following parts: introduction, contents, help, authors, literature.

TABLE 1. LEVELS OF FORMATION OF CREATIVE THINKING OF STUDENTS WITH USE OF ELECTRONIC RESOURCES (ON LEVELS), \%. (EG - 210, KG - 190)

\begin{tabular}{|c|c|c|c|c|c|}
\hline \multirow[t]{2}{*}{ Components } & \multirow[t]{2}{*}{ Levels } & \multicolumn{2}{|c|}{$\begin{array}{l}\text { Before } \\
\text { experiment, \% }\end{array}$} & \multicolumn{2}{|c|}{$\begin{array}{l}\text { After } \\
\text { experiment, } \\
\%\end{array}$} \\
\hline & & $\mathrm{KG}$ & EG & $\mathrm{KG}$ & EG \\
\hline Motivational & $\begin{array}{l}\text { high } \\
\text { average } \\
\text { law }\end{array}$ & $\begin{array}{r}9,2 \\
45,7 \\
45,1\end{array}$ & $\begin{array}{l}10,6 \\
41,4 \\
48,0\end{array}$ & $\begin{array}{l}11,4 \\
46,0 \\
42,6\end{array}$ & $\begin{array}{l}19,3 \\
47,6 \\
33,1\end{array}$ \\
\hline Substantial & $\begin{array}{l}\text { high } \\
\text { average } \\
\text { law }\end{array}$ & $\begin{array}{l}10,2 \\
52,1 \\
37,7\end{array}$ & $\begin{array}{l}12,8 \\
52,2 \\
35,0\end{array}$ & $\begin{array}{l}12,4 \\
57,5 \\
30,1\end{array}$ & $\begin{array}{r}24,7 \\
66,8 \\
8,5 \\
\end{array}$ \\
\hline Procedural & $\begin{array}{l}\text { high } \\
\text { average } \\
\text { law }\end{array}$ & $\begin{array}{r}8,8 \\
38,0 \\
53,2\end{array}$ & $\begin{array}{r}9,8 \\
38,4 \\
51,8\end{array}$ & $\begin{array}{l}11,4 \\
39,5 \\
49,1\end{array}$ & $\begin{array}{l}14,4 \\
48,3 \\
37,3\end{array}$ \\
\hline
\end{tabular}

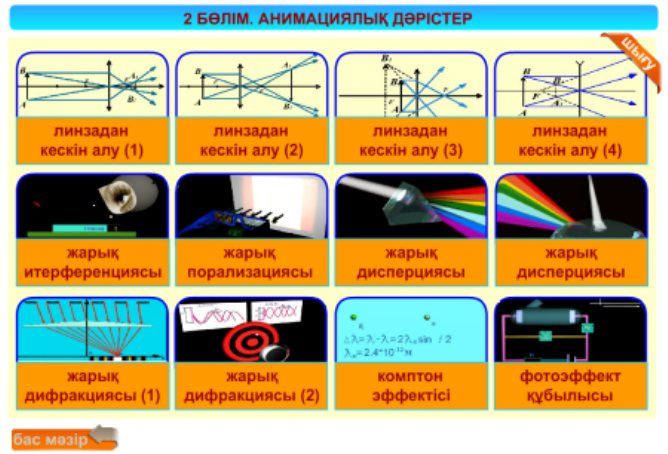

Figure 1. Fragment of electronic textbook "Optics".

The structure of the created electronic textbook allows to be guided easily in its sections. By consideration of structure of the textbook we begin work with the main page. It includes two directions: "Introduction" and "The contents (which was divided into five sections and subjects)".

The created electronic textbook allows to find the necessary information easily, to come back to the previous material, gives the chance to study the material fully which makes the manual attractive, available and in turn well influences the trainee. The maintenance of a material is stated with animation application easily, well and clearly. The text material was supplied by: drawings, tables, the bright examples facilitating perception of a material, tests for controlling students' knowledge according to the previous section.

Results of the research can be used at professional training of future teachers of physics as a material when training the following disciplines: "Optıcs" of the course "Physics", "Technique of Teaching Physics".

As a result of the carried-out test and experimental work the application methods of computer models and experiments of various physical processes and phenomena, as well as virtual laboratory complexes determined the levels of development of the fixed components (motivational, substantial, procedural) and formation of creative thinking (beginning and end of the experiment) of students to use electronic resources (table 1). 


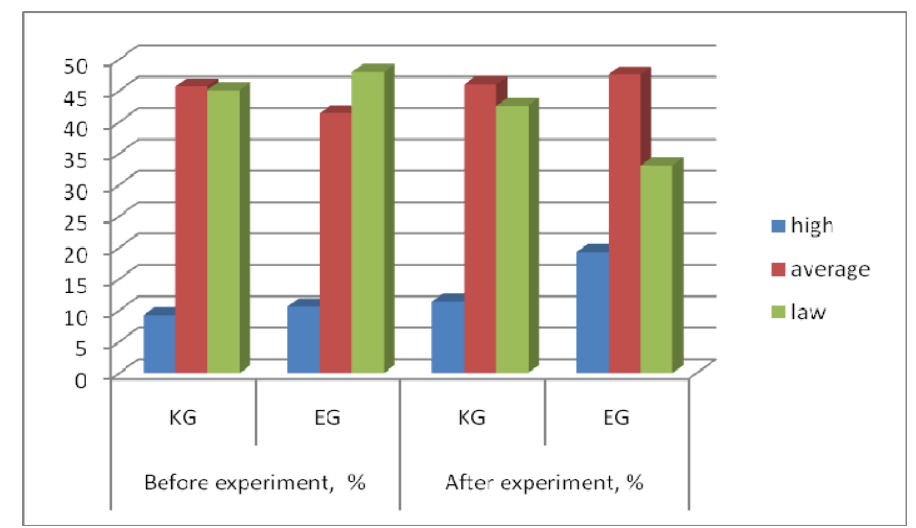

Figure 2. Indicators of the level of development of substantial component in formation of creative thinking of students (\%)

On the experimental final stage of experiment considerable increase of creative thinking of students at application of electronic resources cleared up. If during attributive experiment $35 \%$ of experimental group students showed low level so at the end of experiment only $8,5 \%$ of students showed low level; the average level at the beginning was showed by $52,2 \%$, at the end $66,8 \%$; at the beginning high level showed by $12,8 \%$, at the end their number increased by $24,7 \%$.

\section{CONCLUSIONS}

As a result of the experimental work it was found out that the process of formation of creative thinking of students with computer models use and experiments of various physical processes and the phenomena, and also virtual laboratory complexes becomes successful when meeting the following pedagogical conditions:

- when the physical environment of the educational environment is organized in such a way that raises a number of its quantitative diagnostic parameters (intensity, realizing, emotionality, mobility, activity);

- when the teacher acts not only as the administrator but also as the messenger, the assistant stimulating and participating in creativity of another man, him or herself is a sample of creatively conceiving individual;

- when it is created such program of formation of creative thinking of students which content of the directions, on the one hand, is caused by the content of components of creative thinking, on the other hand, it (contents) is realized in such a way that each of the directions adds other directions thanks to that the components of creative thinking as a whole are enriched.

\section{REFERENCES}

[1] Berkimbayev K.M., G.K. Ormanova., Sh. Zh. Ramankulov., B.A. Kurbanbekov. Formation Of Creative Thinking Of Students On Physics By Means Of Electronic Resources. $3^{\text {rd }}$ World Conference on Innovation and Computer Sciences. p. 570-575. Antalya 2013

[2] Lee H., Kim H.K. Relationships Between Bilingualism and Adaptive Creative Style, Innovative Creative Style, and Creative Strengths among Korean American Students. Creativity Research Journal,.22(4), p.402-407. 2010
[3] Leonard D. and Swap W(2010). Forstering creativity: expert solutions to everyday challenge.

[4] Nguyen Hung San. Sur dung phän mem mäy tinh day hoc bäi "Kinh lup" Vat ly 12 Tap chi Giäo due, № 165, 2007. tr. 34-36.1.

[5] Berkimbayev K.M., Sarybayeva A.Kh., Usembayev I.B., Sh. Zh. Ramankulov. Scientific and Practical Bases of Improvement of Professional Training of Future Specialists - Physics. $3^{\text {rd }}$ World Conference on Innovation and Computer Sciences. p. 251-256 Antalya 2013 